\title{
UMA REFLEXÃO HISTÓRICA CONTEMPORÂNEA DA IMPORTÂNCIA EM COMPREENDER ASPECTOS DA FEBRE AMARELA ${ }^{1}$
}

\author{
HISTORICAL REFLECTION CONTEMPORARY IMPORTANCE OF \\ UNDERSTANDING ASPECTS OF YELLOW FEVER
}

\author{
Wellington Fernando da Silva Ferreira ${ }^{2}$, \\ Elia Machado de Oliveira ${ }^{3}$ e Denecir de Almeida Dutra ${ }^{4}$
}

\section{RESUMO}

O presente estudo objetiva compreender de forma reflexiva as características históricas contemporâneas da patologia febre amarela através de sua importância epidemiológica, bem como diagnósticos e prevenções. Este estudo trata de um descritivo exploratório qualitativo por meio de uma revisão narrativa não sistemática de cunho reflexivo de literatura. Foi realizada a busca de estudos em periódicos nacionais, publicados entre os anos de 2014 e 2018, este recorte temporal justifica-se pela escassez de literatura especifica nas dimensões propostas nesta temática. Dessa forma, na última fase de seleção, foram realizadas as leituras integrais de todos os manuscritos, e amostra final constituída por 30 textos científicos completos. Os resultados apontam o contexto histórico da temática nas últimas décadas, quando a febre amarela tem sido registrada além dos limites da área considerada endêmica (região amazônica). Foi Evidenciado ainda os aspectos clínicos e estrutural e morfológicos da febre amarela e sua diferenciação da dengue. A patologia geoespacial e os vírus em seu ciclo biológico do vetor e os sintomas ao paciente e a imunização da febre amarela e medidas profiláticas. Portanto, fica claro que a febre amarela é uma doença que se proliferou devido ao avanço da urbanização e da ineficácia de políticas públicas para erradicá-la. Logo a melhor forma para proteção é a conscientização da população e a preservação ambiental e prevenção através de imunização.

Palavras-chave: Febre Amarela; Aspectos clínicos; Contexto histórico; Epidemia.

\section{ABSTRACT}

The present study aims to reflect in a reflexive way the contemporary historical characteristics of the disease through its epidemiological importance, as well as diagnoses and preventions. This is a descriptive exploratory qualitative study through a reflective narrative review of the literature. Studies were carried out in national journals, published between 2014 of 2018, the time frame is justified by the scarcity of literature in the proposed dimensions of this theme. Thus, in the last selection phase, the full reading of all manuscripts was carried out, and the final sample consisted of 30 complete scientific texts. The results point to the historical context of the theme in recent decades, where yellow fever has been registered beyond the limits of the area

\footnotetext{
${ }^{1}$ Artigo oriundo de grupo de pesquisa Instituição INTEC e grupo de pesquisa Saúde Coletiva e Geografia da Saúde UNIANDRADE.

${ }^{2}$ Enfermeiro, Especialista em Saúde do Idoso e Gerontologia, Mestre em Saúde Coletiva - Universidade Federal do Paraná - (UFPR). E-mail: wellingtonferreira42@gmail.com

${ }^{3}$ Colaborador - Enfermeira, Especialista em Assistência de Enfermagem ao Paciente em Estado Crítico Fepar, em Comunicação Organizacional - Estácio, em Auditoria em Serviços de Saúde - Uninter, Mestre em Cirurgia - PUCPR, diretora acadêmica Instituição INTEC. E-mail: elia561@hotmail.com

${ }^{4}$ Orientador - Geógrafo, Doutor em Geografia da Saúde pela Universidade Federal do Paraná UFPR, docente titular no Departamento de Enfermagem pelo Centro Universitário Campos de Andrade UNIANDRADE. E-mail: denecir. dutra@terra.com.br
} 
considered endemic (Amazon region). The clinical and structural morphological aspects of yellow fever and dengue differentiation are also evident. The geospatial pathology and virus in its vector biological cycle and the symptoms to the patient and the yellow fever immunization and prophylactic measures. So It is clear, therefore, that yellow fever is a disease that has proliferated due to the advance of urbanization and the ineffectiveness of public policies to eradicate it. Therefore, the best form of protection is the population's awareness and environmental preservation and prevention through immunization.

Keywords: Yellow Fever; Clinical Aspects; Historical Context; Epidemic.

\section{INTRODUÇÃO}

O processo saúde doença sempre esteve enraizado aos cenários culturais e históricos, e durante vários séculos para além da colonização. A entrada de indivíduos escravizados vindos do continente africano para cultivar de maneira explorada as terras brasileiras, em plantios de poderosos e burgueses é um marco qual historicamente não se pode declinar (CASTRO, et al. 2014; MAGALHÃES; MAIO, 2016; LEITE; ERRANTE, 2017; SATO, et al. 2018; SOUZA, et al. 2018).

Contudo, os indivíduos escravizados vinham m navios com baixas condições de sobrevivência e precariamente humano. Assim logo houvera uma gama de proliferação de patologias incomuns a época ao Brasil, tais como as instaladas por hospedeiros em animais e insetos, entre outros, que desenvolveram-se entre às de gravidade histórica: leptospirose; hepatite B; lepra; febre amarela, entre outras possíveis patologias à época (MARTINS, 2015; DONALISIO; FREITA; VON ZUBEN, 2017; AVELINO-SILVA; RAMOS, 2017; DEL CASTILLO, et al. 2018).

Entretanto, muitas destas patologias tornaram-se epidemias, causadoras de altos índices de mortalidade em pessoas que estavam expostas aos fatores de riscos e meios de proliferação da época. Tornaram-se assim uma problemática em saúde pública no decorrer do contexto histórico, até mesmo na contemporaneidade, evidenciando a importância de seu conhecimento e controle para o manejo protetivo quando necessário (RODRIGUES; DE MIRANDA, 2014; OLIVEIRA, et al. 2015; WERMELINGER; CARVALHO, 2016; SEGATA, 2017; JÚNIOR, 2018).

Neste contexto, uma das problemáticas de alta relevância histórica é a febre amarela, a qual é caracterizada como uma patologia de extrema gravidade, causada por um vírus do grupo dos Arbovírus, do gênero Flavivirus, e é transmitida por picada de mosquito. Essa patologia não é contagiosa e apresenta-se epidemiologicamente na forma de silvestre e urbana (GURGEL, et al. 2014; SOUZA, et al. 2015; SAAD; BARATA, 2016; NORONHA; CAMACHO, 2017; OLIVEIRA, et al. 2017; MEDEIROS; DA SILVA BRAGA, 2018).

Somente em meados do século XVII, ocorre o primeiro surto de febre amarela em nível nacional, mais precisamente na região nordeste, com duração de 10 anos para ser controlada. Desta forma com a ampliação territorial a doença se propagou para as demais localidades, acarretando novos casos epidemiológicos graves tornando-as de cunho reemergente (PIMENTA; BARBOSA; 
KODAMA, 2015; GOMES, 2016; MARINHO, et al. 2017; ANAYA, 2017; TESCAROLLO; DOMINGOS; ARAÚJO, 2018).

Para tal, a ausência de preparo e conhecimento da patologia, bem como de seu agente causador da febre amarela impedia o tratamento e sua erradicação naquele período histórico. Dado ao avanço tecnológico da época, Juan Carlos Finlay, médico e cientista cubano, conseguiu identificar o agente causador e com isso surgiram métodos de prevenção (CASTRO, et al. 2014; MAGALHÃES; MAIO, 2016; LEITE; ERRANTE, 2017; SATO, et al. 2018; DE SOUZA, et al. 2018).

Todavia, no século XXI, novos focos de febre amarela estão sendo registrados. Para tal, na contemporaneidade sabe-se, que a febre amarela silvestre e a urbana diferenciam-se, principalmente com relação aos seus vetores, hospedeiros vertebrados e o local de sua ocorrência (LOPES; NOZAWA; LINHARES, 2014; CAVALCANTE; TAUIL, 2016; MALINVERNI, 2017; CAVALCANTE; TAUIL, 2017; SILVA, et al. 2018).

Contudo, para a febre amarela não há tratamento específico, a utilização de terapêuticas medicamentosas tem o intuito de combater os sinais e sintomas da patologia. Cada paciente terá o tratamento conforme suas manifestações, bem como seu quadro clínico, que poderá ser de formas graves, quando recomendar-se-á internação na Unidade de Tratamento Intensivo (UTI). Entretanto, para contextualizar, a vacina contra febre amarela é produzida no Brasil desde 1937, e é reconhecida como segura e eficaz, conforme recomendação de faixa etária (MARTINS, 2015; DONALISIO; FREITA; VON ZUBEN, 2017; AVELINO-SILVA; RAMOS, 2017; DEL CASTILLO, et al. 2018; CASTRO, et al. 2014; MAGALHÃE; MAIO, 2016; LEITE; ERRANTE, 2017; SATO, et al. 2018; SOUZA, et al. 2018; YUZAWA; FERREIRA; OLIVEIRA, 2019).

Portanto, diante da reemergente problemática supracitada ainda há a necessidade de compreender suas características preventivas na febre amarela, desta forma a presente revisão objetiva compreender, de forma reflexiva, as características históricas contemporâneas da doença através de sua importância epidemiológica, bem como diagnósticos e prevenções.

\section{METODOLOGIA}

Trata-se de uma pesquisa bibliográfica de cunho narrativo e reflexivo não sistemático, de caráter exploratório, com abordagem qualitativa. Neste contexto, a revisão apresenta uma síntese pautada em diferentes tópicos. Sendo assim o primeiro passo para a construção do conhecimento científico através de novas teorias e da discussão do assunto de pesquisa (GALVÃO; SAWADA; TREVIZAN, 2004).

Para obtenção dos artigos explorados, realizou-se a seguinte questão norteadora: Quais os aspectos históricos e contemporâneos que faz a febre amarela torna-se reemergente? Foram utilizados os descritores em ciências da saúde (DeCS): "Febre amarela $A N D$ Epidemia; Febre amarela $A N D$ Aspectos clínicos; Febre amarela $A N D$ Notificação $O R$ Incidência”. Os levantamentos das bases das 
pesquisas foram realizados através de bibliotecas públicas e acervos de dados digitais como: Literatura Latino Americana e do Caribe em Ciências da Saúde (LILACS), Scientific Eletronic Library Online (SCIELO), Biblioteca Virtual em Saúde (BVS).

Como critério de inclusão: artigos originais, de revisão e reflexão, com disponibilidade do texto completo em suporte eletrônico, foi estabelecida a utilização de artigos referentes aos anos de 2014 a 2018. Este recorte temporal justifica-se, para observar as publicações em correlação a possíveis marcos teóricos sobre a temática neste período, além de leis e normativas referentes a temática relacionada com foco de interesse, disponibilizados como Brasil no critério País/Região de assunto e idioma português. Os critérios de exclusão: publicações cujo tema principal não correspondiam à questão norteadora da pesquisa, relatos de experiência, artigos internacionais, artigos duplicados em termos de conteúdos nas diferentes bases de dados, e artigos anteriores ao ano de 2014. Assim, o material composto foi de 30 artigos que foram submetidos à técnica de avaliação e análise de conteúdo constituído por três etapas: exploração do referencial teórico, compilação e agrupamento de evidências e interpretação dos resultados.

A primeira etapa possibilitou uma visão geral do conteúdo dos artigos, por meio da leitura dos resumos e fichamento. Os textos na íntegra, após uma primeira leitura, foram organizados. A etapa de exploração do material foi desenvolvida a partir da releitura dos textos, culminando na construção de categorias temáticas de análise. Posteriormente, na etapa de interpretação dos resultados, foram observadas as colocações existentes sob a ótica de diferentes autores.

\section{RESULTADO E DISCUSSÃO}

\section{ASPECTOS EPIDEMIOLÓGICO E CONTEXTO HISTÓRICO CONTEMPORÂNEO}

Para sintonizar a temática, a patologia de febre amarela é existente há mais de 300 anos, com relatos dos povos maias no México, no continente americano em 1648, e na Europa em meados de 1700. Entretanto, somente em 1730 foi noticiada a epidemia que acarretou em aproximadamente 2000 óbitos. Os Estados Unidos da América (EUA) nos séculos XVIII e XIX relataram graves episódios intercorrentes na época (GURGEL, et al. 2014; SOUZA, et al. 2015; SAAD; BARATA, 2016; NORONHA; CAMACHO, 2017; OLIVEIRA, et al. 2017; MEDEIROS; DA SILVA BRAGA, 2018).

Entretanto, em nível nacional a doença possui origens históricas africanas na época da colonização em navios negreiros. Os tripulantes escravizados vieram precariamente, há relatos de má higiene, além do acúmulo de resíduos alimentícios, causando proliferação de muitos micro-organismos propagando as diversas patologias (RODRIGUES; DE MIRANDA, 2014; OLIVEIRA, et al. 2015; WERMELINGER; CARVALHO, 2016; SEGATA, 2017; JÚNIOR, 2018). 
Neste contexto, escravos entravam já doentes nos navios, pois em sua maioria eram capturados e aprisionados, apresentando-se em condições desumanas e beneficiando a transmissão de outras doenças desconhecidas pelo homem na época (LOPES; NOZAWA; LINHARES, 2014; CAVALCANTE; TAUIL, 2016; MALINVERNI, 2017; CAVALCANTE; TAUIL, 2017; SILVA, et al. 2018). Deste modo, o cenário epidêmico inicial no território brasileiro aconteceu, conforme os registros em 1685 no Recife, estado de Pernambuco, onde houve mortes em um período de dez anos. Em 1692 a epidemia incluiu o estado da Bahia com aproximadamente 900 óbitos (LOPES; NOZAWA; LINHARES, 2014; CAVALCANTE; TAUIL, 2016; MALINVERNI, 2017; CAVALCANTE; TAUIL, 2017; SILVA, et al. 2018).

Todavia ao passar dos anos o micro-organismo evidenciava-se ainda pela ausência de conhecimentos e informações, embora aspectos científicos do pesquisador Luís Pasteur, ao redor do mundo, influenciaram os médicos e cientistas da época a correlacionarem a enfermidade às bactérias, bem como ao contágio, por contato físico, e por um possível vetor posterirormente descoberto (CASTRO, et al. 2014; MAGALHÃE; MAIO, 2016; LEITE; ERRANTE, 2017; SATO, et al. 2018; SOUZA, et al. 2018).

Entretanto, havia outros fundamentos e teorias, através de estudos os quais salientavam que a doença não era contagiosa. Juan Carlos Finlay, médico e cientista, apontou que em Havana, Cuba, onde fundamentou em sua teoria, que era necessário um doente, e consequentemente um agente etiológico para transmissão da febre amarela, mas essas ideias não foram aceitas. Mas, em 1878 sua teoria pode ser evidenciada como correta, onde um mosquito, poderia ser responsável por causar a filariose humana (MARTINS, 2015; DONALISIO; FREITA; VON ZUBEN, 2017; AVELINO-SILVA; RAMOS, 2017; DEL CASTILLO, et al. 2018).

Contudo, somente através de experimentações laboratoriais das espécies, Culex quinquefasciatus e Stegomia fasciata, comuns a lugares onde havia relato de febre amarela, pode ser comprovado de forma científica. Não obstante, somente nos anos de 1900, o EUA refizeram os experimentos de Juan Carlos Finlay, e perceberam que os transmissores estavam incorretos, pois o verdadeiro vetor é o Aedes aegypti, o qual atualmente também é transmissor das doenças Dengue, Chikungunya e Zika vírus (PIMENTA; BARBOSA; KODAMA, 2015; GOMES, 2016; MARINHO, et al. 2017; ANAYA, 2017; TESCAROLLO; DOMINGOS; ARAÚJO, 2018).

Para tal, no Brasil, o cientista Emilio Ribas, médico brasileiro de destaque, efetivou a campanha de combate ao mosquito no estado de São Paulo em 1904, juntamente com reconhecido medico da época, Oswaldo Cruz, pioneiro na medicina preventiva e curativa no Brasil (RODRIGUES; DE MIRANDA, 2014; OLIVEIRA, et al. 2015; WERMELINGER; CARVALHO, 2016; SEGATA, 2017; JÚNIOR, 2018).

Desta forma, o pesquisador Oswaldo Cruz tivera péssimas condições bem como outras dificuldades para o manejo preventivo junto a população, tais como demanda de imigrantes, culminando com a falta de recursos em pesquisas científicas, embora por sua capacidade intelectual foi nomeado diretor geral do Instituto Butantã ampliando assim suas iniciativas nas temáticas endêmicas 
(GURGEL, et al. 2014; SOUZA, et al. 2015; SAAD; BARATA, 2016; NORONHA; CAMACHO, 2017; OLIVEIRA, et al. 2017; MEDEIROS; DA SILVA BRAGA, 2018).

Entretanto, abusivos atos foram considerados por olhares da população, a vacinação obrigatória em massa por meio da invasão das residências, e a obrigatoriedade de notificação de casos. A população em decorrência do desconhecimento das operações sanitárias que geravam discórdia, tornam a época um marco qual foi denominada 'revolta da vacina', título que é reconhecido nas passagens históricas sobre a imunização brasileira (LOPES; NOZAWA; LINHARES, 2014; CAVALCANTE; TAUIL, 2016; MALINVERNI, 2017; CAVALCANTE; TAUIL, 2017; SILVA, et al. 2018).

Corroborando a isto, a imprensa noticiava que era ação desnecessária, porém, ficou provado que estas campanhas, estavam controlando as doenças. Posteriormente o denominado, "Conselho do Povo" foi criado com o intuito de orientar e esclarecer, eventuais desconhecimentos dos papeis das campanhas. Entretanto, somente em 1907 no $14^{\circ}$ Congresso Internacional de Higiene e Demografia de Berlim na Alemanha, os atos sanitários pela erradicação da febre amarela, recebeu seu conhecimento através de premiação pelo trabalho desenvolvido no Brasil (CASTRO, et al. 2014; MAGALHÃE; MAIO, 2016; LEITE; ERRANTE, 2017; SATO, et al. 2018; DE SOUZA, et al. 2018).

\section{ASPECTOS CLÍNICOS E ESTRUTURAIS MORFOLÓGICOS DA FEBRE AMARELA E DIFERENCIAÇÃO DA DENGUE}

Quanto à epidemiologia da temática, o denominado mosquito Aedes aegypti é originalmente de características Egípcias e sua disseminação é realizada através das grandes navegações históricas, africanas para as Américas e Ásia conforme contextualizada na literatura. Em meados de 1762, o Aedes aegypti cientificamente era conhecido como Culex aegypti (mosquito do egípcio), porém, espécie Aedes aegypti tem características morfológicas e biológicas semelhantes aos de outras espécies do gênero Aedes, descritas a partir de 1800 (LOPES; NOZAWA; LINHARES, 2014; CAVALCANTE; TAUIL, 2016; MALINVERNI, 2017; CAVALCANTE; TAUIL, 2017; SILVA, et al. 2018).

O mosquito é estruturalmente pequeno em comparação aos demais, da cor preta listrada com a cor branca, asas translúcidas e inaudível ao humano. Se a fêmea já encontrar-se contaminada, os descendentes virão a ter o vírus. Para tal, tem sua predominância em regiões tropicais e subtropicais, caracterizada pelos hábitos cinantrópicos e antropogênicos, pois eles dependem tanto de ambientes propícios para criadouros e de sangue humano para o amadurecimento dos ovos. Desta forma, só as fêmeas se alimentam do sangue, assim depositam aproximadamente 150 à 200 ovos por vez, e pode alcançar a marca de 1500 ovos durante toda sua fase adulta, que é em média de 30 dias. Já os machos alimentam-se exclusivamente de frutas (MARTINS, 2015; DONALISIO; FREITA; VON ZUBEN, 2017; AVELINO-SILVA; RAMOS, 2017; DEL CASTILLO, et al. 2018). 
Em relação aos ovos em especifico, têm por característica formato alongado de cor escurecida e brilhante, que podem ser encontrados em recipientes com capacidade de armazenamento de líquidos, e em ocos de árvores, podendo resistir mais de 400 dias em período de seca. Com a chuva ou acúmulo de água, os ovos eclodem em menos de 30 minutos, os quais irão passar por 4 fases de mudança (ovo, larva, pupa e estrutura adulta) e em aproximadamente 9 dias, um novo mosquito é formado (RODRIGUES; DE MIRANDA, 2014; OLIVEIRA, et al. 2015; WERMELINGER; CARVALHO, 2016; SEGATA, 2017; JÚNIOR, 2018).

Deste modo, a epizootias, por conceito evidenciado nas ciências veterinária e ecologia, é definido como enfermidade contagiosa através de surtos endêmicos em animais de uma região ao mesmo espaço de tempo, propagando-se com enorme rapidez. É um aspecto essencial no ciclo da febre amarela e um indicador importante que serve de alerta a possíveis surtos em humanos (LOPES; NOZAWA; LINHARES, 2014; CAVALCANTE; TAUIL, 2016; MALINVERNI, 2017; CAVALCANTE; TAUIL, 2017; SILVA, et al. 2018).

Contudo, a febre amarela silvestre tem em seu ciclo a epizootias, em macacos brasileiros e o mosquito pertencente ao gênero Haemagogus, vetor da forma silvestre da doença. O hospedeiro macaco, desempenha as funções, de amplificador e disseminador do vírus. O mosquito é considerado um vetor reservatório do vírus, responsável pela dispersão. A dispersão ocorre com facilidade em amplos centros urbanos, devido à ausência de vacinação e medidas preventivas. A contaminação do homem é pelo contato aos mosquitos do gênero Haemagogus em áreas epidêmicas pontuais. Neste contexto, para o controle da dispersão é necessário que a população se vacine e que ocorra planos de cuidados para a não facilitação da reprodução do mosquito (PIMENTA; BARBOSA; KODAMA, 2015; GOMES, 2016; MARINHO, et al. 2017; ANAYA, 2017; TESCAROLLO; DOMINGOS; ARAÚJO, 2018).

\section{PATOLOGIA GEOESPACIAL: VÍRUS EM SEU CICLO BIOLÓGICO DO VETOR E OS SINTOMAS AO PACIENTE}

Com relação ao vírus da febre amarela, o ribovírus (vírus contendo ácido ribonucleicos, formados por RNA), são constituídos por capa proteica chamada de capsídeo envolvendo o ácido nucleico, denominando-se núcleo capsídeo. O vírus necessita de fatores para se reproduzir, como por exemplo o enriquecimento do metabolismo celular, que vão invadindo com capsídeo ou introduzindo apenas seu material genético no interior das células, utilizando-se, de suas substâncias existentes a fim de multiplicar seu próprio material genético (CASTRO, et al. 2014; MAGALHÃES; MAIO, 2016; LEITE; ERRANTE, 2017; SATO, et al. 2018; SOUZA, et al. 2018).

Neste contexto a patologia decorrente da febre amarela na África se caracteriza por ciclo de transmissões silvestres, com hospedeiro definitivo, o macaco como transmissor do vírus para outros 
primatas ou humanos. A infecção nos humanos ocorre quando há a invasão do habitat dos transmissores ou migração dos vetores, dos mosquitos do gênero Aedes sendo as espécies Aedes africanus, Aedes simpsoni, Aedes furcifer, Aedes luteocephalus e Aedes taylori (LOPES; NOZAWA; LINHARES, 2014; CAVALCANTE; TAUIL, 2016; MALINVERNI, 2017; CAVALCANTE; TAUIL, 2017; SILVA, et al. 2018). Entretanto, quanto a febre amarela no continente americano, pode desenvolver pela transmissão sistêmica ocorrendo por ciclo silvestre e urbano, conforme o ambiente. No ciclo silvestre são os mosquitos do gênero Haemagogus e Sabethes, com o hospedeiro definitivo primata macacos dos gêneros Allouata, Cebus, Atelles e Callithrix. O ciclo urbano no vetor do vírus é o mosquito Aedes aegypti, de transmissão do vírus de homem para homens (PIMENTA; BARBOSA; KODAMA, 2015; GOMES, 2016; MARINHO, et al. 2017; ANAYA, 2017; TESCAROLLO; DOMINGOS; ARAÚJO, 2018).

Quanto aos sintomas caracterizando a febre amarela, é uma patologia de face infecciosa febril e aguda de período breve, de agravamento variável causada pelo arbovírus. Neste contexto a vacinação é a forma principal de evitar e combater a patologia. Deve ser aplicada 10 dias antes para quem for realizar viagem para lugares classificados como risco. Há de salientar que a vacina é disponível em todas as unidades básicas de saúde de todos os municípios brasileiros gratuitamente (GURGEL, et al. 2014; SOUZA, et al. 2015; SAAD; BARATA, 2016; NORONHA; CAMACHO, 2017; OLIVEIRA, et al. 2017; MEDEIROS; DA SILVA BRAGA, 2018).

A febre amarela provoca queixas álgicas de abdômen, nas costas, músculos, além de episódios de náuseas, afetando o aparelho gastrointestinal, sensações de calafrios, fadiga, febre alta, mal estar ou perda de apetite e é comum confusão mental, cefaleia, hemorragia (gengiva, nariz, estômago, intestino e urina) e icterícia (coloração da pele e olhos amarelado) (LOPES; NOZAWA; LINHARES, 2014; CAVALCANTE; TAUIL, 2016; MALINVERNI, 2017; CAVALCANTE; TAUIL, 2017; SILVA, et al. 2018).

Ao que tange ao tratamento da febre amarela não há ações específicas, mas em caso de hospitalização deve-se salientar o monitoramento de fluidos, ingestão de líquidos ou da aplicação da terapia intravenosa, em necessidade de reposição de perdas sanguíneas em casos graves, que podem gerar problemas cardíacos, renais e hepáticos fatais e caso o paciente infectado não receber uma assistência médica imediata poderá ir a óbito (MARTINS, 2015; DONALISIO; FREITA; VON ZUBEN, 2017; AVELINO-SILVA; RAMOS, 2017; DEL CASTILLO, et al. 2018).

\section{IMUNIZAÇÃO DA FEBRE AMARELA E MEDIDAS PROFILÁTICAS}

Referente a vacina que propõe a imunização e proteção, evidenciou a literatura, inquietação com doenças ocasionadas por vírus advindas de muitos tempos, que visavam a necessidade da criação de método eficiente que atingisse somente células infectadas pelos vírus. Neste contexto, em 1799 o pesquisador inglês Edward Jenner, criou a primeira vacina contra a cowpox, doença idêntica a varíola. Em seguida, novos estudos toaram como base ao combate a distintas enfermidades ocasionada por 
vírus infecciosos (RODRIGUES; DE MIRANDA, 2014; OLIVEIRA, et al. 2015; WERMELINGER; CARVALHO, 2016; SEGATA, 2017; JÚNIOR, 2018).

No ano de 1936, Max Theiler e Henry Smith, da Fundação Rockefeller, instituição encarregada por pesquisas da febre amarela, desenvolveram a cepa 17D, caracterizada como um vírus atenuado. Inicialmente foi verificada sua efetividade em ratos e embriões de galinha em nível experimental. Posteriormente a vacina estava sendo testada no território brasileiro, em estudo na região de Minas Gerais, através de imunização de 5 mil pessoas (CASTRO, et al. 2014; MAGALHÃE; MAIO, 2016; LEITE; ERRANTE, 2017; SATO, et al. 2018; SOUZA, et al. 2018).

Neste contexto a então desenvolvida vacina da febre amarela, teve como primazia a de concepção de um vírus atenuado da patologia. Para tal, a vacina é cientificamente altamente imunogênica, assim conferindo uma imunidade de cerca de 95\%, tolerada e com baixíssimos efeitos colaterais, como febre, mialgia e cefaleia (PIMENTA; BARBOSA; KODAMA, 2015; GOMES, 2016; MARINHO, et al. 2017; ANAYA, 2017; TESCAROLLO; DOMINGOS; ARAÚJO, 2018).

Ao que tange as orientações para imunização contra febre amarela, a vacina está indicada tão-somente em circunstâncias de emergência epidemiológicas ou viagem para área caracterizadas como de risco, entretanto conforme alterações no cenário ambiental e epidemiológico, situações foram atualizadas em locais específicos e regiões de possíveis epidemias em nível nacional nos últimos anos. Portanto, imuniza-se os cidadãos de 9 meses até o fim do $4^{\circ}$ ano, uma dose aos 9 meses e outra aos 4 anos de idade. Pessoas a partir de 5 anos, que receberam a dose única da vacina estão imunizadas e não precisam mais se imunizar para esta vacina. Aos que nunca foram vacinados será a dose única da vacina. Quanto aos indivíduos de 60 anos ou mais somente após avaliação médica. Quanto as gestantes a vacinação possuem contraindicação (GURGEL, et al. 2014; SOUZA, et al. 2015; SAAD; BARATA, 2016; NORONHA; CAMACHO, 2017; OLIVEIRA, et al. 2017; MEDEIROS; DA SILVA BRAGA, 2018).

Para bebês, a imunização vacinal é contraindicada até que o lactante complete seis meses de vida. Os viajantes internacionais devem seguir as recomendações do "Regulamento Sanitário Internacional', e quando ocorrer viagens para áreas de recomendação de vacina no Brasil, vacina-se pelo menos 10 dias antecedentemente a viagem (LOPES; NOZAWA; LINHARES, 2014; CAVALCANTE; TAUIL, 2016; MALINVERNI, 2017; CAVALCANTE; TAUIL, 2017; SILVA, et al. 2018).

Quanto ao controle da patologia, oriundas de vetores, através de espécies de mosquitos sempre são um grande desafio, tanto para as estratégias da população quanto para as táticas de planejamento dos governos. Portanto, aspectos como a infraestrutura precária, a incompetência na coleta de lixo e a contaminação das águas, afetam a totalmente os métodos profiláticos (RODRIGUES; DE MIRANDA, 2014; OLIVEIRA, et al. 2015; WERMELINGER; CARVALHO, 2016; SEGATA, 2017; JÚNIOR, 2018).

Perante a necessidade de reduzir e extinguir as doenças é possível a utilização de alguns processos dinâmicos de ações, como o controle mecânico, o qual consiste no combate ao vetor, pela 
eliminação dos criadouros do mosquito, assim como as filtragens de reservatórios de água e instalações de estruturas com telas em janelas das residências (MARTINS, 2015; DONALISIO; FREITA; VON ZUBEN, 2017; AVELINO-SILVA; RAMOS, 2017; DEL CASTILLO, et al. 2018).

Quanto ao controle biológico, o qual consiste no uso de predadores naturais ao mosquito, como peixes e sapos, alimentando-se de larvas como dos mosquitos adultos, bem como a utilização de patógenos que anulem o desenvolvimento das larvas, como bactérias, fungos, parasitas e larvicidas (CASTRO, et al. 2014; MAGALHÃE; MAIO, 2016; LEITE; ERRANTE, 2017; SATO, et al. 2018; SOUZA, et al. 2018).

Referente ao controle químico, realizado através do uso de produtos químicos que mantém diretamente o vetor, como os inseticidas e repelentes. Há ainda as formas de prevenção por meio da implantação da vigilância sindrômica em máximo número de estados, tornando a vigilância epidemiológica efetiva e eficaz (GURGEL, et al. 2014; SOUZA, et al. 2015; SAAD; BARATA, 2016; NORONHA; CAMACHO, 2017; OLIVEIRA, et al. 2017; MEDEIROS; DA SILVA BRAGA, 2018).

\section{CONCLUSÃO}

A partir dos aspectos correlacionados, percebeu-se a importância desse tipo de pesquisa para a compreensão dos contextos históricos, contribuindo para o entendimento de como os problemas se apresentam no nosso cotidiano, em meio à realidade social no qual estamos inseridos.

Conforme supracitado, a febre amarela possui origens históricas, sendo trazida dos navios negreiros na época da colonização. Essa doença possui ciclo urbano e silvestre, apresentando através do Aedes aegypti vetores Haemagogus da forma silvestre da patologia. Assim, sua proliferação tende a ser facilitada pelo processo de urbanização, juntamente com o desmatamento e com as péssimas condições sanitárias.

Além disso, a melhor maneira de prevenir a doença é pela imunização vacinal, entretanto, ainda há o medo de realizá-la devido aos possíveis efeitos colaterais e/ou movimentos contemporâneos anti-vacinais. Portanto, conclui-se que a febre amarela é uma patologia que se proliferou devido ao avanço da urbanização e da ineficácia de políticas públicas governamentais com o efetivo objetivo de erradicá-la. Desta forma, compreender as características históricas contemporâneas da doença através de sua importância epidemiológica e prevenções, deve-se ao comportamento evolutivo e histórico e também como aconteceu a construção de estratégias em saúde e as características dos países em desenvolvimento, listando assim um ponto crítico e reflexivo da problemática em saúde pública, a ter mais visibilidade e resolutividade. 


\section{REFERÊNCIAS}

ANAYA, Gabriel Lopes. A Erradicação do Aedes aegypti: Febre amarela, Fred Soper e saúde pública nas Américas (1918-1968). Varia Historia, v. 33, n. 62, p. 561-564, 2017.

AVELINO-SILVA, Vivian Iida; RAMOS, Jessica Fernandes. Arboviroses e políticas públicas no Brasil/

Arboviruses and public policies in Brazil. Revista Ciências Em Saúde, v. 7, n. 3, p. 1-2, 2017.

BRASIL. Ministério da Saúde. Campanha de vacinação terá dose fracionada de febre amarela em três estados. Net. 2018. Disponível em: https://bit.ly/32zVNuC. Acesso em: 20 fev. 2019.

BRASIL. Ministério da Saúde. Ministério da Saúde atualiza casos de febre amarela. Net. 2018. Disponível em: https://bit.ly/3k1O8G9. Acesso em: 20 fev. 2019.

CASTRO, Ana Luiza de et al. Avaliação da cobertura vacinal em crianças de um a dois anos pelo Monitoramento Rápido de Cobertura em Vespasiano. Rev Med Minas Gerais [Internet], v. 24, p. S15-20, 2014.

CAVALCANTE, Karina Ribeiro Leite Jardim; TAUIL, Pedro Luiz. Características epidemiológicas da febre amarela no Brasil, 2000-2012. Epidemiologia e Serviços de Saúde, v. 25, p. 11-20, 2016.

CAVALCANTE, Karina Ribeiro Leite Jardim; TAUIL, Pedro Luiz. Risco de reintrodução da febre amarela urbana no Brasil. Epidemiologia e Serviços de Saúde, v. 26, p. 617-620, 2017.

DEL CASTILLO, José Maria et al. Avaliação ecocardiográfica das alterações cardíacas tardias provocadas pela Febre Chikungunya. Arq Bras Cardiol: Imagem cardiovasc, v. 31, n. 3, p. 183-190, 2018.

DONALISIO, Maria Rita; FREITAS, André Ricardo Ribas; VON ZUBEN, Andrea Paula Bruno. Arboviroses emergentes no Brasil: desafios para a clínica e implicações para a saúde pública. Revista de Saúde Pública, v. 51, p. 1-6, 2017.

GALVÃO, Cristina Maria; SAWADA, Namie Okino; TREVIZAN, Maria Auxiliadora. Revisão sistemática: recurso que proporciona a incorporação das evidências na prática da enfermagem. Revista Latino-Americana de Enfermagem, v. 12, n. 3, p. 549-556, 2004. 
GOMES, Raimundo Nonato Silva. Políticas de saúde pública no brasil: contexto histórico. Revista Augustus, v. 21, n. 42, p. 127-136, 2016.

GURGEL, Cristina Brandt Friedrich Martin et al. Fragmentos da história da higiene e saúde públicas: a febre amarela em Campinas-SP no século XIX. Revista de Patologia Tropical/Journal of Tropical Pathology, v. 43, n. 2, p. 111-120, 2014.

JÚNIOR, Vitor Laerte Pinto. A Febre Amarela como nova ameaça sanitária. Revista de Medicina e Saúde de Brasília, v. 6, n. 3, 2018.

LEITE, Alberto Andrade; ERRANTE, Paolo Ruggero. Aspectos clínicos, prevenção e epidemiologia da Febre Amarela no Brasil. UNILUS Ensino e Pesquisa, v. 14, n. 34, p. 169-184, 2017.

LOPES, Nayara; NOZAWA, Carlos; LINHARES, Rosa Elisa Carvalho. Características gerais e epidemiologia dos arbovírus emergentes no Brasil. Revista Pan-Amazônica de Saúde, v. 5, n. 3, p. 55-64, 2014.

MAGALHÃES, Rodrigo Cesar da Silva; MAIO, Marcos Chor. Seja bem-vindo vizinho: a viagem de Heitor Praguer Fróes pelos Estados Unidos e a reconstrução da campanha contra a febre amarela nas Américas (1943-1947). História (São Paulo), v. 35, 2016.

MALINVERNI, Claudia. Uma epizootia, duas notícias: a febre amarela como epidemia e como não epidemia. Revista Eletrônica de Comunicação, Informação e Inovação em Saúde, v. 11, n. 2, 2017.

MARINHO, A. K. B. B. et al. Vacina contra a febre amarela: reações adversas e populações de risco. Arq Asma Alerg Imunol, v. 1, n. 3, p. 245-256, 2017.

MARTINS, Valter. Cidade-laboratório: Campinas e a febre amarela na aurora republicana. História, Ciências, Saúde-Manguinhos, v. 22, n. 2, p. 507-524, 2015.

MEDEIROS, Ingredy Elkana Andrade Ferreira; DA SILVA BRAGA, Geovania Maria. Efeitos sociais provocados pelo aumento do número de casos de doenças transmitidas pelo mosquito Aedes aegypti no município de Balsas, Maranhão. PUBVET, v. 12, p. 131, 2018. 
NORONHA, Tatiana Guimarães de; CAMACHO, Luiz Antonio Bastos. Controvérsias sobre a ampliação das áreas com vacinação de rotina contra a febre amarela no Brasil. Cadernos de Saúde Pública, v. 33, p. e00060917, 2017.

OLIVEIRA, Luzilene Barbosa et al. Perfil do uso populacional de inseticidas domésticos no combate a mosquitos. Semina: Ciências Biológicas e da Saúde, v. 36, n. 1, p. 79-92, 2015.

OLIVEIRA, Stefanie Griebeler et al. Discursos referentes à febre amarela no contexto da primeira república. Revista Contexto \& Saúde, v. 17, n. 33, p. 215-230, 2017.

PIMENTA, Tânia Salgado; BARBOSA, Keith; KODAMA, Kaori. A província do Rio de Janeiro em tempos de epidemia. Dimensões, n. 34, p. 145-183, 2015.

RODRIGUES, Marinéa da Silva Figueira; DE MIRANDA, Antonio Carlos. História Ambiental: o saneamento da cidade do Rio de Janeiro. Revista Práxis, v. 6, n. 11, 2014.

SAAD, Leila Del Castillo; BARATA, Rita Barradas. Surtos de febre amarela no estado de São Paulo, 2000-2010. Epidemiologia e Serviços de Saúde, v. 25, p. 531-540, 2016.

SATO, Ana Paula Sayuri et al. Uso de registro informatizado de imunização na vigilância de eventos adversos pós-vacina. Rev. Saúde Pública, v. 52, p. -, 2018.

SEGATA, Jean. O mosquito da indiferença. Revista Estudos Feministas, v. 25, n. 2, p. 975-978, 2017. SILVA, Clécia Pereira de et al. Um estudo bibliográfico acerca dos surtos de Febre Amarela no Brasil. Revista Brasileira de Meio Ambiente, v. 2, n. 1, 2018.

SOUZA, Maria Neide de Ramalho et al. NOVAS ESTRATÉGIAS DE IMUNIZAÇÃO CONTRA A FEBRE AMARELA. Revista Científica da Faculdade de Educação e Meio Ambiente, v. 9, n. edesp, p. 584-589, 2018.

SOUZA, Raquel Lima et al. Monitoramento Entomológico em área de ocorrência de febre amarela silvestre no oeste da Bahia. Saúde Pública, v. 39, p. 136-140, 2015. 
TESCAROLLO, Iara Lucia; DOMINGOS, Aline Garcia; ARAÚJO, Carlos Eduardo Pulz. Dados epidemiológicos relacionados à febre amarela no município de vinhedo. Revista Ensaios Pioneiros, v. 2, n. 1, p. 12-19, 2018.

WERMELINGER, Eduardo Dias; CARVALHO, Raimundo Wilson de. Métodos e procedimentos usados no controle do Aedes aegypti na bem-sucedida campanha de profilaxia da febre amarela de 1928 e 1929 no Rio de Janeiro. Epidemiologia e Serviços de Saúde, v. 25, p. 837-844, 2016.

YUZAWA, Lucineia Satiko; FERREIRA, Wellington Fernando da Silva; OLIVEIRA, Elia Machado de. Políticas Públicas Brasileira de Imunização e Educação Permanente: Um Recorte Temporal Bioético/ Brazilian Public Policies on Immunization and Permanent Education: A Temporary Bioethic Cutting. ID on line Revista De Psicologia, v. 13, n. 45, p. 95-110, 2019. 